\title{
POLÍTICAS DE DIVERSIDADE NAS ORGANIZAÇÕES: AS RELAÇÕES DE TRABALHO COMENTADAS POR TRABALHADORES HOMOSSEXUAIS
}

\section{Diversity Policies in organizations: labor relations reviewed by gay male workers}

\author{
Ana Paula Rodrigues Diniz \\ Núcleo de Estudos Organizacionais e Sociedade, NEOS-CEPEAD - UFMG \\ anaprdiniz@hotmail.com \\ Alexandre de Pádua Carrieri \\ NEOS-CEPEAD - UFMG \\ alexandre@cepead.face.ufmg.br \\ Gislaine Gandra \\ UFMG \\ gislaine_g@hotmail.com \\ Renata de Almeida Bicalho \\ NEOS - CEPEAD - UFMG \\ rabicalho@yahoo.com.br
}

\begin{abstract}
Resumo
O objetivo deste artigo foi analisar a experiência profissional de homossexuais masculinos, a partir das vivências e percepções dos mesmos a respeito das políticas de diversidade nas organizações. Para tanto, realizamos uma pesquisa de abordagem qualitativa, na qual se empregou o método biográfico como metodologia. A coleta dos dados se procedeu com trabalhadores residentes em diferentes capitais brasileiras, sendo os relatos apreciados segundo categorias da Análise do Discurso. Por meio das ponderações do empírico, foi possível observar que o percurso semântico das políticas de diversidade é claramente marcado por uma temática: o descompasso entre o discurso e a prática. Tal tema foi fundamentado pelos sujeitos de pesquisa de modo distinto, destacando-se entre as razões a perpetuação das violências e das barreiras, a má atuação dos gestores ou, até mesmo, a descrença nas possibilidades de mitigação do preconceito por meio dessas práticas. Atreladas a essa discussão, diferentes propostas para otimizar/ incrementar a eficiência das políticas foram apresentadas: punição dos atos homofóbicos, observação das questões culturais, comunicação clara da proposta e revisão do papel do gestor. Findamos, assim, com algumas reflexões, as quais visam a contribuir para melhorias nas relações de trabalho e na gestão de pessoas.
\end{abstract}

Palavras-chave: Políticas de diversidade, sexualidade nas organizações, trabalhadores homossexuais masculinos, relações de trabalho. 


\begin{abstract}
The aim of this paper was to analyze the experience of gay men, from the experiences and perceptions of them about the sexual diversity policies implemented in organizations. Therefore, we performed a qualitative study, in which we used the biographical method as methodology. Data collection was done on gay male workers living in different Brazilian cities, being further examined the reports by some categories of Discourse Analysis. Through the analysis of empirical, it was observed that the semantic route of diversity policies is clearly marked by a theme: the gap between the discourse and practice. This theme was founded by respondents in different ways, foremost among the reasons for the perpetuation of violence and barriers, poor performance of the managers or even disbelief in the possibilities of mitigating the bias through these practices. Interlaced with this discussion, various proposals to enhance / improve the efficiency of antidiscrimination policies were presented, including: the punishment of homophobic acts, observation of cultural issues, clear communication of the proposal and review of the role of manager. Ended, so this work with some reflections, which aim to contribute to improvements in labor relations and personnel management.
\end{abstract}

Keywords: Diversity policies, sexuality in organizations, gay male workers, labor relations. 


\section{Introdução}

O objetivo do presente artigo foi analisar a experiência profissional de homossexuais masculinos a partir das vivências e percepções dos mesmos a respeito das políticas de diversidade sexual implementadas nas organizações. Justificamos essa proposta pela pertinência do escopo adotado, o qual possibilita refletir sobre a atual realidade social em que o trabalhador não-heterossexual é objeto de preconceito, bem como sobre a maneira como essas desigualdades têm sido tratadas nas organizações.

Enquanto parte do tema da sexualidade, a homossexualidade tem sido objeto de estudo nos meios acadêmicos no Brasil desde o século XIX, quando médicos higienistas desenvolveram diversas teses que, em sua maioria, buscavam medidas para eliminar os efeitos supostamente maléficos da mesma (GÓIS, 2004). Somente no final do século XX, podemos encontrar pesquisas abordando a homossexualidade de forma menos preconceituosa, enfocando as dificuldades que os homossexuais enfrentam na sociedade brasileira e as estratégias que utilizam na tentativa de superar a opressão da qual são vítimas.

Apesar do crescimento dos estudos que envolvam essa temática, há ainda uma carência de trabalhos especializados que enfoquem a homossexualidade no ambiente de trabalho. Para Ferreira (2007), a homossexualidade tem sido discutida pelo seu caráter inferior e desviante, sendo vista como atributo anormal e estranho que revela padrões de comportamento e convívio social não determinados pela sociedade. A autora enfatiza que a herança cultural brasileira deixou a homossexualidade no campo do proibido, em que falar, defender, produzir conhecimento ao seu redor e lutar por sua visibilidade era entendido como transgressão.

Segundo Siqueira e Zauli-Fellows (2006), no contexto da diversidade no ambiente de trabalho, pode-se dizer que um dos grupos mais marginalizados nas empresas é o dos homossexuais, devido ao heterossexismo e à homofobia. Além de ser uma minoria, esse tem maiores dificuldades que os outros grupos minoritários de obter os próprios direitos, em especial nas empresas em que trabalham. Associado a isso, uma vez que a sociedade brasileira tem, em geral, a categoria heterossexual como referencial de normalidade, os homossexuais tornam-se alvo frequente de violência moral (GUEDES, 2003).

Nesse contexto maculado pelo preconceito, a Gestão de Pessoas, embalada pelas propostas do movimento da Responsabilidade Social, dentre outras transformações sociais, institui e difunde nas diversas organizações as políticas de diversidade, entre as quais se destacam as políticas de diversidade sexual. $\mathrm{O}$ intuito desta política consiste, em suma, em combater a discriminação operada em face dos não-heterossexuais, viabilizando não só a equidade social, mas também a redução de conflitos no espaço organizacional, a atração e retenção de talentos e a adição de valor para a empresa (INSTITUTO ETHOS, 2008; FLEURY, 2000).

No entanto, mesmo com todo o discurso da diversidade cultural e da riqueza em se valorizar a diferença, a discriminação baseada na orientação sexual se perpetua no ambiente de trabalho (CHUNG, 1995). Pesquisas recentes (e.g. IRIGARAY, 2007; ECCEL; FLORESPEREIRA, 2008) apontam a ineficiência das políticas de diversidade no cenário organizacional, as quais enfrentam inúmeras dificuldades para serem praticadas de forma efetiva. Irigaray (2007) ressalta o preconceito arraigado por parte dos membros organizacionais, a permissividade gerencial e a falta de senso coletivo de diversidade como principais razões para a perpetuidade da marginalização.

Tendo em vista a escassez e expressividade de estudos empíricos sobre a inserção do homossexual no ambiente de trabalho, assim como a pouca efetividade das políticas de diversidade já denunciada, analisamos nesse artigo a trajetória profissional de homossexuais 
masculinos, enfocando as vivências e percepções dos mesmos acerca de tais políticas. O que se pretendeu com essa proposta foi não só evidenciar as questões atinentes à aplicabilidade das políticas, mas, sobretudo, elucidar as experiências, avaliações, interpretações e sugestões dos próprios homossexuais a quem essas se destinam, buscando, com isso, refletir sobre as relações de trabalho e a Gestão de Pessoas.

Para tanto, realizamos uma pesquisa de abordagem qualitativa, na qual se empregou o método biográfico como metodologia. $\mathrm{O}$ emprego desse método mostrou-se adequado por permitir a reconstrução das trajetórias profissionais dos sujeitos de pesquisa e, com isso, delinear as vivências e percepções acerca do objeto em estudo. Para a coleta de dados, foram realizadas entrevistas com trabalhadores homossexuais masculinos residentes nas capitais Aracajú, Belo Horizonte, Brasília, Porto Alegre, Rio de Janeiro, São Paulo e Vitória. Ao final da fase de campo, levantamos 81 relatos, os quais foram apreciados segundo algumas categorias da Análise do Discurso.

Esse artigo está desenvolvido em seis partes distintas e complementares. Após a presente introdução, apresentamos uma discussão a respeito da inserção do homossexual no ambiente de trabalho e outra sobre implantação da política de diversidade sexual nas organizações. Logo após, expomos a metodologia de pesquisa adotada seguida pela análise dos dados empíricos. Findamos o artigo com algumas reflexões, as quais visam a contribuir para melhorias nas relações de trabalho e na Gestão de Pessoas. 


\section{O homossexual no ambiente de trabalho}

A análise do contexto organizacional pode envolver algumas dimensões e o impacto dessas nas relações interpessoais, as quais raça, gênero, classe social, escolaridade e orientação sexual. Destacamos, para fins deste trabalho, o tema da sexualidade, o qual é ainda pouco discutido no âmbito dos Estudos Organizacionais, apesar dos efeitos potenciais da mesma na vida dos sujeitos e em suas relações com os grupos aos quais pertence. Especificamente nessa seção, trataremos da problemática do homossexual no ambiente de trabalho para, em seguida, discorrermos sobre a sexualidade nas organizações e as políticas de diversidade.

Ao discutirmos a condição do homossexual, seja no trabalho ou nas demais esferas da vida em sociedade, se faz imprescindível a consideração do contexto de dominação masculina no qual estamos inseridos. Como afirma Bourdieu (2007, p. 63-64), ser homem, na sociedade moderna, significa ser nobre e esse status decorre de

um trabalho social de nominação e de inculcação, ao término do qual uma identidade social instituída por uma dessas 'linhas de demarcação mística' conhecidas e reconhecidas por todos, que o mundo social desenha, inscreve-se em uma natureza biológica e se torna um habitus, lei social incorporada.

Essa lei se constrói a partir das relações de dominação estabelecidas entre homens e mulheres e entre homens e homens, pautadas nas diferenças de gênero, no primeiro caso, e nas desigualdades referentes à etnia, sexualidade, geração, entre outras, no segundo caso (KIMMEL, 1998).

É interessante ressaltar que a existência da dominação mencionada não suplanta a multiplicidade de formas que a masculinidade pode tomar. De acordo com Connell (1998), distintas masculinidades surgem em diferentes culturas e, em uma mesma cultura, em contextos sócio-históricos díspares, coexistem variadas masculinidades. Em decorrência dessa pluralidade, os modos de ser homem se organizam em relações de hierarquia e exclusão, culminando no estabelecimento de masculinidades hegemônicas, as quais exercem uma dominância sobre aquelas menos valorizadas.

A masculinidade hegemônica é entendida como uma representação histórico-social, cultural e espaço-temporal construída, que estabelece os padrões de normalidade no modo de ser dos homens. O homem "normal" caracteriza-se por ser branco, heterossexual, cristão, sem deficiências, viril e ativo. Nesse sentido, aqueles que se diferenciam em quaisquer desses aspectos, fugindo do arquétipo estabelecido de "macho" dominante, são considerados "anormais", como os homossexuais masculinos sujeitos dessa pesquisa (CONNELL, 1998; KIMMEL, 1998). Kimmel (1998) destaca que, em decorrência dessa delimitação do que pertence ou não ao universo masculino, o sexismo e a homofobia emergiram como traço marcante das diferentes masculinidades.

A representação de hegemonia de uma masculinidade relaciona-se com a expressão "grandes-homens", de Godelier (1996), a qual denota um homem com poder e privilégios empregados nas relações de dominação estabelecidas com mulheres e com outros homens, ou seja, o topo de uma hierarquia social. Essa se mantém por meio das disputas de poder, que, sucessivamente, depreciam aquele que é diferente. Ressaltamos que essa masculinidade não atinge todos de maneira semelhante, uma vez que cada sujeito relaciona-se de forma particular com os padrões vigentes. Além disso, as masculinidades são fluidas e dinâmicas, sendo, portanto, passíveis tanto de remodelações quanto de contestações. Entretanto, é importante considerar que essa representação dita dominante ainda é compartilhada pela grande maioria (CONNELL, 1998; KIMMEL, 1998). 
Nesse contexto de dominação masculina, maculado pelo preconceito, os nãoheterossexuais tornam-se alvo de recorrentes violências (GUEDES, 2003). Umbelino (2008) verificou que os homossexuais experimentam um tipo de discriminação específico, baseado nos mitos e estereótipos que se encontram enraizados nos padrões culturais e educacionais da sociedade, e que tal imaginário não caracteriza fielmente a população homossexual. Entre estes estereótipos estão: a crença generalizada de que os homossexuais masculinos se encontram predominantemente em ocupações tidas como "femininas", tais como cabeleireiro, designer e dançarino; a noção de que os homossexuais não possuem relacionamentos monogâmicos e duradouros; a idéia de que os homossexuais masculinos comportam-se "femininamente"; e a crença de que o sexo entre os homossexuais é imoral, sendo os mesmos pessoas promíscuas.

Designadamente no cenário organizacional, Siqueira e Zauli-Fellows (2006) apontam que o trabalhador homossexual é objeto de piadas homofóbicas, é desprezado e não tem os mesmos direitos, visíveis ou não, do funcionário heterossexual, mesmo no que se refere ao direito ao plano de saúde para o parceiro. "Salienta-se, entretanto, que a problemática que se discute é muito maior do que o direito ao plano de saúde para o parceiro e engloba também relações assimétricas de poder nas organizações e as relações existentes em uma sociedade que tem na norma a heterossexualidade" (SIQUEIRA; ZAULI-FELLOWS, 2006, p. 7).

Autores como Croteau e Hedstrom (1993), Elliott (1993) e Sanches (2006) afirmam haver barreiras encontradas pelos homossexuais no ambiente de trabalho, tais como discriminação, homofobia, estereótipos negativos, estigmas sociais e o medo infundado da AIDS. Sanches (2006) acredita que, de forma geral, ainda existem nas relações de trabalho homossexuais que deixam de ser contratados, são despedidos ou têm sua carreira profissional prejudicada por fatores que se prendem claramente à orientação sexual inferida ou assumida. Este preconceito arraigado na mentalidade heterossexista, ou até mesmo homofóbica de muitos empregadores, não é embasado em qualquer prova ou fundamento que justifique a atitude discriminatória.

Na mesma direção, temos a pesquisa de Ferreira (2007). Em suas conclusões, a autora, a partir da ótica do assédio moral e da negação de direitos, reconhece a questão das punições e sanções no ambiente de trabalho em virtude da orientação sexual. Apesar de não ter encontrado essas vivências no grupo de entrevistados, ela discute que as barreiras existem de forma velada nas organizações, porquanto não são dados aos homossexuais direitos, oportunidades e tratamentos compatíveis com aqueles conferidos aos heterossexuais. Ademais, Ferreira (2007) chama a atenção para a inexistência de proteções legais contra a violência aos homossexuais - como as concedidas para as minorias raciais, no que se refere ao caso brasileiro -, expondo-os às diversas ações gerenciais, como retaliação e exclusão social dentro da empresa, entre outros.

Frente a tantas barreiras, o trabalhador homossexual enfrenta um dilema que é o de assumir sua orientação sexual ou mantê-la em segredo. Esta decisão torna-se extremamente delicada quando se considera o ambiente de trabalho marcado pela competitividade, pelas relações de poder e pela eminente ameaça de ser vítima de violência. Se por um lado, a revelação pode acarretar consequências negativas, como violências, discriminação, preterimento em alguma promoção ou até mesmo demissão; por outro, a omissão incorre em sofrimentos atrelados ao fato de não se sentir integral ou à necessidade de sempre esconder sua identidade das outras pessoas. De qualquer forma, a decisão tende a provocar impactos na saúde psíquica e, porque não dizer, física dos sujeitos (FERREIRA, 2007; WARD; WINSTANLEY, 2005).

Mediante o preconceito operado em face dos homossexuais e o sofrimento por eles vivenciado, cumpriu-se formular, no contexto organizacional, algumas práticas de combate à 
discriminação. A construção de tais políticas foi também influenciada, e quiçá determinada, por questões de ordem gerencial, como a promoção de satisfação e motivação e a construção de uma imagem positiva da organização frente ao mercado, entre outras. No próximo tópico, nos dedicaremos a essa discussão, visando a lançar luz sobre a questão das as políticas de diversidade implementadas nas organizações. 


\section{As políticas de diversidade nas organizações}

A questão da diversidade cultural nas organizações tem emergido como um importante tópico, em países como Estados Unidos e Canadá, desde a década de 1960, quando foram promulgadas algumas leis visando à mitigação do preconceito racial observado nas empresas e nas instituições de ensino. Nos Estados Unidos, as ações afirmativas determinaram que as empresas que mantinham contratos com o governo ou que deste recebiam recursos deveriam diversificar o corpo de funcionários, acompanhando a diversidade encontrada no mercado de trabalho em que atuavam. Já no Canadá, em modelo semelhante ao norte-americano, em 1986, foram estabelecidos o Employment Equity Act e o Federal Contractors Program, em uma tentativa de conferir maiores oportunidades aos grupos historicamente marginalizados (FLEURY, 2000).

A partir dos anos 1990, o tema ganhou forte expressão também na academia e, em especial, nos Estudos Organizacionais. O avanço das pesquisas sobre essa temática, de acordo com Nkomo e Cox Jr. (1999), deveu-se à averiguação do aumento da diversidade da força de trabalho e dos possíveis impactos que tal diversidade desencadearia no desempenho das organizações. Em uma perspectiva pragmática, a diversidade passou a ser tratada como um recurso a ser gerido no contexto organizacional, com o intuito de atenuar suas desvantagens e potencializar suas vantagens (FLEURY, 2000; GALEÃO-SILVA; ALVES, 2002; FLORESPEREIRA; ECCEL, 2010).

O movimento da Responsabilidade Social configurou, da mesma forma, um motor na inserção da temática da diversidade no âmbito das organizações, seja por questões éticas e/ou econômicas. De acordo com o Instituto Ethos (2008), uma empresa socialmente responsável é aquela que "vai além da obrigação de respeitar as leis, pagar impostos e observar as condições adequadas de segurança e saúde para os trabalhadores, e faz isso por acreditar que assim será uma empresa melhor e estará contribuindo para a construção de uma sociedade mais justa". Essa proposta envolve ações voltadas para o público externo, como consumidores, fornecedores, governo, sociedade e outras instituições, e para o público interno à organização.

A prática da responsabilidade social internamente à organização se dá, segundo o Instituto, por meio da construção de um ambiente de trabalho saudável, pautado em condições favoráveis para a realização das atividades; no desenvolvimento pessoal e profissional dos funcionários e no estreitamento das relações com os mesmos; e no respeito às culturas locais, às minorias e às instituições que as representam. No que tange à diversidade, tem-se que

a empresa não deve permitir qualquer tipo de discriminação em termos de recrutamento, acesso a treinamento, remuneração, avaliação ou promoção de seus empregados. Devem ser oferecidas oportunidades iguais às pessoas, independente do sexo, raça, idade, origem, orientação sexual, religião, deficiência física, condições de saúde, etc. Atenção especial deve ser dada a membros de grupos que geralmente sofrem discriminação na sociedade (INSTITUTO ETHOS, 2008, grifos nossos).

Vale destacar que, apesar de explicitarem em seus pressupostos para a configuração de uma empresa socialmente responsável a não discriminação por orientação sexual e a defesa a membros subjugados na sociedade, nenhuma ação afirmativa para a inclusão dos nãoheterossexuais é proposta, como é feito com relação às mulheres e aos negros.

Neste contexto, difundiram-se entre as diversas organizações as políticas de diversidade, as quais abrangiam "[o] cumprimento de metas no que diz respeito à contratação de pessoas dos grupos-alvo da política de diversidade e [o] gerenciamento da diversidade dentro da empresa" (GALEÃO-SILVA; ALVES, 2002, p. 7). Como dito anteriormente, a fundamentação dessa proposta não se restringiu às questões éticas, abarcando também 
interesses econômicos e gerenciais atrelados à administração de conflitos e à construção de vantagens competitivas. Como argúi Fleury (2000, p. 21 e 24)

o objetivo principal da gestão da diversidade cultural é administrar as relações de trabalho, as práticas de emprego e a composição interna da força de trabalho a fim de atrair e reter os melhores talentos dentre os chamados grupos de minoria. [...] Em outras palavras, administrar a diversidade deve adicionar valor à companhia.

Hebl e Griffith (2002) alegam que o apoio da organização aos homossexuais, com a criação de políticas e normas antidiscriminatórias, favorece o comprometimento e motivação do sujeito e a atenuação dos conflitos. E Carrieri (2008) discute que a inserção dos nãoheterossexuais no ambiente de trabalho tem sido apoiada pelos gestores, dado não só a maior flexibilidade de horários e a possibilidade de realocação dos mesmos entre as sedes da empresa, por não possuírem vínculos matrimoniais e filhos como limitadores; como também o maior empenho observado nesse grupo, uma vez que os não-heterossexuais buscam, por meio do desempenho, alcançar igual reconhecimento destinado aos heterossexuais. Observase assim que esses sujeitos, até então completamente excluídos das preocupações das organizações, tornaram-se alvo de interesse, na medida em que se mostraram trabalhadores com o perfil desejado (PRADO; MACHADO, 2008), e o gerenciamento da diversidade passou a ser entendido como favorável à gestão organizacional e ao alcance de seus objetivos.

Apesar do esforço destinado à criação de tais políticas, estudos recentes revelam que essas não se efetivaram em plenitude, uma vez que "o preconceito está arraigado no campo das idéias e manifesta-se mesmo onde se diz combatê-lo" (GALEÃO-SILVA; ALVES, 2002, p. 9). Irigaray (2007, p. 13) ratifica tal consideração, afirmando que

os discursos empresariais, embora se apresentem formalmente estruturados na forma de políticas organizacionais claras, encontram dificuldades de serem praticados efetivamente devido a processos arraigados de preconceito por parte dos próprios empregados, de certo nível de permissividade gerencial, e pela ausência de senso coletivo de diversidade.

Eccel e Flores-Pereira (2008) ressaltam ainda que as políticas de diversidade não promovem a igualdade por meio da melhoria das condições de trabalho, bem como não conferem maiores oportunidades aos grupos discriminados. Neste sentido, as autoras argumentam que tais políticas acabam por mascarar "as diferenças, pois exclui o seu caráter político, e toma a diversidade como mais um recurso organizacional a ser administrado em busca de melhores resultados" (ECCEL; FLORES-PEREIRA, 2008, p. 4). Eccel e FloresPereira (2008) destacam também que as políticas de diversidade voltadas para homossexuais, na forma como são implementadas atualmente, reafirmam e reforçam o padrão heteronormativo tido como "normal", perpetuando a marginalização de tudo o que é diferente.

Tendo em vista a ineficiência já denunciada por esses autores, o presente artigo objetivou analisar a experiência profissional de homossexuais masculinos a partir das vivências e percepções dos mesmos a respeito das políticas de diversidade sexual implementadas nas organizações. Como dito, o que se pretendeu, com essa proposta, foi extrapolar as questões atinentes à aplicabilidade de tais políticas, enfatizando também as experiências, avaliações, interpretações e sugestões dos próprios homossexuais a quem essas se destinam, visando, isso posto, às melhorias nas relações de trabalho e na Gestão de Pessoas. Para tal, apresentaremos a seguir os procedimentos metodológicos que nortearam essa pesquisa e, logo após, os resultados alcançados.

\section{Caminhos percorridos}


Para o alcance do objetivo traçado, optamos pela realização de uma pesquisa qualitativa. Tal escolha se justificou por colocar o sujeito no epicentro epistemológico e ontológico da pesquisa, permitindo o entendimento do fenômeno a partir da percepção daqueles que vivenciam o cotidiano estudado. Faz-se importante atentar, contudo, para algumas especificidades dessa abordagem, entre as quais se destacam as amostras intencionais, escolhidas por tipicidade ou acessibilidade; as técnicas de coleta de dados pouco estruturadas; as análises de cunho interpretativo; e os resultados não generalizáveis (VERGARA, 2005).

O procedimento escolhido para obtenção dos dados foi o método biográfico com coletas de trajetórias pessoais e profissionais por investigação participativa. Utilizamos o método biográfico, "[...] cujo objetivo seja - a partir da totalidade sintética que é o discurso específico de um indivíduo - reconstruir uma experiência humana vivida em grupo e de tendência universal" (MARRE, 1991, p. 89). E focamos nas trajetórias pessoais e profissionais, que permitiram compreender a realidade dos sujeitos, caminhando para a "construção de um objeto científico, cujo fundamento é um conjunto real e histórico de relações sociológicas e empíricas vividas por um grupo [ou um sujeito], mas captadas através de histórias de vida. Essas poderão ser consideradas totalidades sintéticas. Cada uma forma o todo" (MARRE, 1991, p. 110).

As trajetórias foram coletadas por meio de entrevistas semi-estruturadas realizadas com trabalhadores homossexuais masculinos inseridos em organizações públicas ou privadas. As entrevistas foram efetuadas nas capitais Aracajú, Belo Horizonte, Brasília, Vitória, Porto Alegre, Rio de Janeiro e São Paulo. Para a coleta dos relatos, foi formada uma rede de pesquisadores, os quais ficaram responsáveis pela captação e realização de entrevistas com sujeitos de pesquisa residentes em tais capitais e que atendessem aos seguintes critérios: (1) ter trajetória profissional no mercado superior a cinco anos; (2) acessibilidade; (3) disposição do indivíduo em cooperar com a pesquisa; e (4) aptidão em fazer confidências sem constrangimento.

Para compor o corpus, empregamos dois critérios qualitativos interrelacionados: diversificação e saturação (MARRE, 1991). O critério de diversificação refere-se à escolha de pessoas diferenciadas, que são capazes de analisar, em um contexto amplo, a totalidade ou quase de temas, fatos e juízos. Ressaltamos que, nessa pesquisa, associada à heterogeneidade na escolha dos sujeitos de pesquisa residentes em uma mesma cidade, a inclusão de diferentes capitais contribuiu para a diversificação e aprofundamento do conhecimento sobre a vivência pessoal e profissional dos trabalhadores homossexuais masculinos. Já em relação ao critério de saturação, o tamanho do corpus foi flexível e não definido a priori, e a coleta dos dados encerrou-se quando a repetição de temáticas e conteúdos apontaram para um padrão discursivo.

Ao final da fase de campo, coletaram-se 81 relatos, os quais foram apreciados segundo algumas categorias da Análise do Discurso (FERNANDES, 2005) seguindo a corrente francesa. De acordo com Maingueneau (1998), a análise do discurso busca vincular a enunciação a um lugar social. Nesse sentido, observamos que, uma das vantagens oferecidas por essa técnica, é a possibilidade de uma interpretação dos relatos que não se restrinja ao explícito, mas sim, trabalhe as ideologias implícitas no discurso. Conforme aborda Carrieri (2001), os discursos estão relacionados a determinadas visões de mundo que balizam o comportamento dos sujeitos e que, assim sendo, podem ser entendidos como uma rede de relações estabelecida pelos mesmos. Por fim, ressaltamos que ideologias não são compreendidas neste trabalho segundo o seu caráter político, mas sim, representam as idéias e percepções que amparam as falas. 
A análise foi realizada por trechos das entrevistas, que estão numerados de 01 a 13 , e os enunciadores foram identificados pela sequência de E1 a E81, objetivando preservar suas identidades. Nessa, algumas categorias foram detalhadas, as quais: (1) Percursos semânticos e temas: Os percursos semânticos caracterizam-se pela repetição de elementos que perpassam e relacionam o discurso (RODRIGUES, 2004). (2) Seleções lexicais: parte-se da noção de que o emprego de determinadas palavras contribui para a argumentação do enunciador e, nesse sentido, não podem ser encaradas como escolhas aleatórias. (3) Relações entre explícitos e implícitos: os implícitos são aqueles argumentos que, por motivos quaisquer, não foram claramente elucidados pelo narrador, mas que, no entanto, deixam "pistas" para o interlocutor. Nesse trabalho, foram empregados os implícitos pressupostos, resultantes de uma relação lógica com o apresentado nos relatos, e os subentendidos, frutos de inferências realizadas pelo pesquisador. (4) Delineamento de personagens: entende-se que a construção de personagens discursivas também contribui para a coerência da argumentação do narrador e pode, inclusive, apontar relações metonímicas, nas quais se toma a parte pelo todo. (5) Silenciados: questões que não se encontram na enunciação, mas que podem estar relacionadas ao discurso (FARIA; LINHARES, 1993).

Ressaltamos, por fim, que nos trechos analisados os fragmentos considerados relevantes para a apreciação foram destacados pelo recurso itálico, com o intuito de chamar a atenção do leitor para as diferentes partes que fundamentaram a análise realizada. 


\section{Políticas de diversidade: vivências, críticas e sugestões}

Por meio das ponderações do empírico, foi possível observar que o percurso semântico das políticas de diversidade é claramente marcado por uma temática: o descompasso entre o discurso e a prática. Tal tema foi fundamentado pelos sujeitos de pesquisa de modo distinto e, baseados nessas constatações, diferentes propostas para otimizar/ incrementar a eficiência das políticas antidiscriminatórias foram apresentadas. Nesse contexto, perpassaremos nessa seção desde avaliações e vivências até sugestões apontadas pelos entrevistados, para, com isso, refletirmos sobre a atual realidade social em que o trabalhador homossexual está inserido, bem como sobre a gestão organizacional e, de modo mais específico, o trabalho da diversidade.

Primeiramente, salientamos o trecho 01 de E26, no qual o enunciador apresenta sua descrença na política de diversidade:

(01) É chique políticas contra homofobia, políticas para incluir o parceiro no plano de saúde, no plano de previdência. Mas é porque é chique. Eu não acho que aquelas cabeças pensantes que nós temos, eu não acho que elas, se não tivesse esse viés político por trás, que elas fariam. Eu não tenho a menor dúvida de que não fariam. Eu já vi, em encontros fora do trabalho, eles contam piadas do fulano, que acham que o fulano é gay e riem. Nossa, riem tanto! Então, existem políticas contra toda essa questão de preconceito, mas no relacionamento pessoa a pessoa, eu não tenho a menor dúvida de que existe discriminação [...] [Só contra os homossexuais ou no geral?] Contra tudo. Contra gay, contra negro... (E26)

O enunciador, de início, questiona a ideologia que fundamenta a adoção das políticas de diversidade nas organizações, qualificadas por ele como chique. O lexema destacado, de acordo com o contexto, pode ser relacionado com a intenção de se consolidar a imagem da organização enquanto socialmente responsável, colocando-a entre aquelas que adotam as melhores práticas ou as práticas que estão em voga no momento. Tal questionamento é enfatizado em Eu não tenho a menor dúvida de que não fariam, atestando que, para E26, a real motivação para a implementação dessas medidas refere-se às questões políticas mencionadas e não à preocupação com a inserção dos homossexuais no ambiente de trabalho. Em seguida, o entrevistado introduz a temática do descompasso entre o discurso e a prática, afirmando que, por mais que as políticas sejam adotadas nas organizações, as violências identificadas nas piadas e nos deboches implícitos na seleção lexical riem - se perpetuam. Associado a isso, a expressão cabeças pensantes sugere que tal ineficiência pode estar também pautada na má atuação dos gestores, ficando silenciadas, contudo, possíveis fundamentações para essa consideração. Por fim, ressaltamos que os preconceitos não são dirigidos apenas aos homossexuais, mas também às demais minorias, como os negros e outras implícitas em tudo.

A má atuação dos gestores, sugerida por E26, foi abordada por outros enunciadores como causa para o descompasso entre o discurso e a prática. E24, no fragmento 02, ao relatar suas vivências, explicita a negligência dos responsáveis pela gestão de pessoas perante uma situação de assédio, devido ao despreparo dos mesmos. Já E10 alega que a postura preconceituosa dos gestores, denominada conservadora, os impede de conferir direitos igualitários às minorias, impossibilitando, dessa forma, que gays, prostitutas ou negros assumam cargos mais altos na hierarquia. Observamos ainda a existência de barreiras sutis, relacionadas ao tratamento e à concessão de direitos e oportunidades distintos para os diferentes grupos, questão essa também tratada por E43 e E55 nos excertos seguintes. 
(02) Então, eu registrei uma denúncia contra [os assediadores] e eu acredito que [a chefe do setor de pessoal] não foi lá interceder por mim. Porque, inclusive, ela falou: "Olha, eu não sei lidar com essas coisas". (E24)

(03) As chefias carregam ainda uma postura conservadora. As chefias não vão querer, ocupando um cargo de grande hierarquia, uma prostituta, um homossexual, um negro. (E10)

E43, no trecho 04, introduz a temática do descompasso entre o discurso e a prática, fundamentando-a, como dito anteriormente, na inexistência de direitos e oportunidades igualitárias para as diferentes minorias coexistentes nas organizações, com destaque para as mulheres. No mesmo sentido, temos o relato 05 de E55, no qual o entrevistado afirma que as políticas de diversidade não conseguiram suplantar as barreiras enfrentadas pelos homossexuais. Essas barreiras estão relacionadas à dificuldade de revelar a identidade sexual nas organizações, às sanções e/ou punições arbitrárias e às perdas de chances de promoção. Importante notar que, da mesma forma que E26 no fragmento 01, E55 questiona a real motivação para a implementação das políticas de diversidade e trata tais políticas como algo de menor valor ou de pouca efetividade, argumento explícito em toma uma esmolinha e sugerido pela expressão blá-blá-blá e pela restrição da abrangência das medidas às questões políticas, respectivamente. Ademais, salientamos a ênfase dada pelos entrevistados à perpetuação das violências no âmbito organizacional, as quais, como menciona E55, apresentam-se cada vez mais escamoteadas e sutis.

(04) Vê quem é que ocupa as funções-chave: gerente, o gerente principal, o gerente só da baixa gerência administrativa, gerente administrativa... Você vai ver o mínimo de mulheres ocupando essa posição. Então, dizer que não existe discriminação, os mais vários tipos de discriminação, existe sim. (E43)

(05) Esse blá-blá-blá politicamente correto de diversidade só serve para aliviar a consciência pesada dos héteros e venderem a imagem de politicamente correto. [Você acha isso mesmo?] Sim. Vale para gays, negros, deficientes. É só para dizer toma uma esmolinha. [...] tenho amigos que trabalham em empresas assim e não têm espaço para se assumirem. Outros que se assumiram, foram demitidos algum tempo depois ou nunca conseguiram promoção. [E você acha que é porque eles são gays?] Só pode ser. [Nenhuma outra possibilidade.] Não, é discriminação, só que disfarçada. (E55)

Outra fundamentação para o descompasso entre discurso e prática, já apontada por E55, refere-se ao real espaço conferido aos homossexuais para revelação de sua orientação sexual. Como discutido no percurso teórico, a questão da revelação, principalmente no contexto organizacional, constitui um dilema para os gays, sendo o incentivo à "saída do armário" uma importante pauta das políticas antidiscriminatórias. $\mathrm{O}$ que se percebe por meio dos relatos, entretanto, é que os homossexuais se sentem impelidos a ocultarem a sua identidade sexual. E40, no trecho 06, argumenta que aqueles que destoam do padrão tido como "normal" nas organizações são preteridos. O lexema dupla remete à noção de que somente o homossexual que consiga atuar de modo a transparecer uma identidade heterossexual, ou seja, que se "travista" de heterossexual, ocultando quaisquer traços associados ao feminino, não sofrerá discriminações, como a perda de chances de promoção citada. Nesse sentido, o enunciador introduz em seu discurso as personagens discursivas coletivas "deficientes físicos", "travestis" e "pessoas feias", as quais são consideradas alvos certos da marginalização, dado a impossibilidade de encobrirem as características que as tornam minorias. 
(06) [Sobre as políticas de diversidade sexual] Eu acho que na prática há um problema. Eu acho que só se uma pessoa for, digamos, não muito clara, digamos, uma pessoa que seja dupla, que vai conseguir ascender muito. A gente vai ficar em ambientes, assim como eles deixam pessoas feias, assim como eles deixam deficientes físicos... este pessoal também, digamos, é uma anomalia. Apesar de ter muita capacidade, eu acho que são pessoas que vão ficar, se for muito claro: eu sou homossexual, vão ficar mais em áreas internas [...] travestis, seria inconcebível. [E se um travesti passa num concurso, o que se faz?] Eles vão colocar ele como colocam um deficiente físico. (E40)

Ainda no debate sobre a revelação da identidade sexual, observamos que, de acordo com o fragmento acima, o preconceito refere-se não só às barreiras de ascensão, mas abrange também a limitação aos cargos internos ou àqueles em que não se tem contato com os clientes, o que é corroborado por E22 no excerto 07. Salientamos que subentendida nesses relatos está a intenção de se evitar que a associação minoria-organização seja feita pelos próprios membros da organização e/ou pela sociedade, como se tal associação fosse depreciativa para a imagem organizacional. Destacamos também que a palavra de ordem instituída - Seja, mas não assuma - configura-se uma violência, uma vez que se estabelece uma "ameaça", mesmo que sutil, que impõe que ou os indivíduos omitem a identidade sexual ou sofrerão preconceitos; e que se atenta diretamente contra as pulsões dos mesmos.

(07) Se ele percebe que é uma pessoa que tem um comportamento assim... Como eu poderia dizer? Que levantasse alguma suspeita, eles colocam normalmente esse pessoal para trabalhar no serviço administrativo. Porque ele não vai estar muito no dia-a-dia na rua, mais ou menos assim. [...] Porque a política deles é bem essa, direcionar você assim: "Seja, mas não assuma! Seja, mas não levante bandeira! Seja, mas não declare!’. É uma política bem por esse caminho. (E22)

Além das diferentes razões elucidadas, as quais se ancoram primordialmente em disfunções na implementação das políticas, o descompasso entre o discurso e a prática foi justificado pela descrença dos enunciadores de que a marginalização e a subalternização das minorias possam ser mitigadas por meio das práticas implementadas no contexto organizacional. E29, no relato 08, afirma que as ações investidas para a conscientização dos membros organizacionais, como os cursos, não são capazes de alterar a concepção preconceituosa de um sujeito, argumento explícito em quando a pessoa é preconceituosa, ela é preconceituosa!. Implícita no discurso está a noção de que o preconceito é uma construção que acompanha a trajetória dos sujeitos e, nesse sentido, ao se inserirem nas organizações, esses possuem suas crenças arraigadas.

(08) [Você acha que as políticas são efetivas?] Acho que não funciona muito. Acho que quando a pessoa é preconceituosa, ela é preconceituosa! Não é um curso que vai mudar. Nós vivemos num país que a educação, nós não temos uma educação que discuta as diferenças na escola. A gente, lá na escola, a gente não discute, porque nós vivemos num país miscigenado, nós temos negros, índios, brancos, amarelos, pardos e tudo mais. E aí, está lá na certidão do cara: ele é pardo. E ele vai viver a vida inteira falando que ele é pardo, ele não é negro. E a escola também não vai discutir isso com ele. A professora vai perceber que o aluno, ele tem uma tendência homossexual masculina ou feminina, ela não vai ter espaço para discutir aquilo. (E29)

Outra questão que emerge no fragmento acima se refere ao papel dos educadores no processo de desnaturalização das bases de moralidade instituídas. E29, após expor sua descrença na eliminação do preconceito por meio das políticas de diversidade, discute a ausência de debates sobre as diferenças no âmbito escolar, bem como apresenta duas causas 
explícitas para essa carência. A primeira justificativa apontada relaciona-se à miscigenação brasileira, a qual, como aponta Fleury (2000), contribui para a construção de um imaginário de um país sem preconceitos. Já a segunda alude à reafirmação da diferença, delimitando aqueles que pertencem ou não a determinados grupos e baseando, assim, a discriminação. Conjuntamente às duas razões explícitas, observamos um terceiro motivo implícito e associado, designadamente, à homossexualidade. Ao final do relato, o enunciador afirma que a professora, ao notar que um aluno ou aluna tenha tendência homossexual, ou seja, ao perceber que um aluno ou aluna detém traços sócio-historicamente associados ao sexo oposto, ela não vai ter espaço para discussão. A expressão destacada sugere que, nesse caso, o não posicionamento da educadora advém não de uma negligência ou da naturalização da subalternização, mas sim, de uma impossibilidade de discutir a temática, possivelmente em função das barreiras culturais arroladas à sexualidade. Por fim, salientamos que pressuposto nos argumentos apresentados, está a concepção de que por meio da educação na escola se poderia alcançar o questionamento ou, até mesmo, a desnaturalização do preconceito.

Diferentemente de E29, outros entrevistados posicionaram-se favoravelmente em relação às políticas de diversidade, apresentando, inclusive, possíveis caminhos para a sua prática efetiva. Primeiramente, a necessidade de observância das questões culturais foi enfatizada. Conforme discutido, a não efetividade das políticas de diversidade está intrinsecamente relacionada com a perpetuação das violências, as quais são pautadas em valores e crenças arraigados. Nesse sentido, E9 e E25, nos excertos 09 e 10, ressaltam a importância de se construir outras significações, por meio de novas socializações e experiências. A partir das seleções lexicais normal e naturalizar, presentes nos trechos, podese pressupor que, para os entrevistados, tais significações permitiriam tirar o homossexual da condição de anormalidade, de estranho, e colocá-lo na de normalidade, viabilizando assim a aceitação das diferenças. Outra questão relevante refere-se ao apontamento de E25 naquilo que tange as punições e/ou sanções, consideradas fundamentais no processo de combate à marginalização.

(09) Eu acho que devia criar uma nova cultura. Colocar na cabeça das pessoas uma forma diferente de pensar, uma forma diferente de amar, uma forma diferente de respeitar. Ver o homossexual como uma pessoa normal, um ser humano normal. (E9)

(10) Eu acho que as empresas, elas têm que naturalizar. Como elas podem naturalizar isso? Trazer seminários, debates, discussões, para dentro do mercado de trabalho $e$ também punir quando tiver alguma discriminação. (E25)

As questões atinentes à comunicação também foram apontadas como determinantes para a efetivação das políticas de diversidade. E28, ao relatar sua experiência no trecho 11 , reforça a importância de que as políticas sejam formalizadas e explicitadas de modo claro, para que todos se conscientizem sobre a diversidade, bem como sobre as consequências negativas que uma atitude discriminatória pode acarretar. Destaque deve ser dado à importância que o enunciador atribui às sanções, dado que, para ele, a noção e o receio dos malefícios de uma ação preconceituosa constituem um primeiro passo para que as pessoas se policiem e, com isso, não violentem as minorias. Ressaltamos também a segurança que E28 apresenta de que, caso seja agredido, será amparado, mesmo que tais agressões ocorram de forma despercebida, como se pode observar em mesmo brincando. Da mesma forma, percebemos implicitamente no relato 12 de E44 a relevância da comunicação. O entrevistado afirma não se incluir no programa, por temer que sua identidade sexual seja revelada para outras pessoas. Salientamos, assim, a obscuridade desse processo, à medida que E44 ao invés de se sentir protegido, sente-se ainda mais ameaçado pela política de diversidade. 
(11) A organização vem cada vez sendo mais explícita nesses cursos que a gente faz, de que isso [a diversidade] existe e tem que ser respeitado. Então, gerou esse código de ética. Isso cria também uma coisa de que ninguém pode também chegar, como talvez no passado tenha acontecido, chegar, levantar da sua cadeira e falar: "Fica calado aí seu isso, seu aquilo, seu aquilo outro, mesmo brincando". Então, as pessoas, eu vejo que hoje, se policiam muito. Tem até uma rigidez muito grande com relação ao assédio moral. Qualquer um pode um dia dizer: "Olha você está me assediando, eu vou reclamar". [...] São ganhos. Isso vai fazendo que as pessoas primeiro se policiem, quer dizer, elas tomam uma consciência, talvez, por força da regra. (E28)

(12) Eu ainda tenho medo de chegar ao RH e falar. Pode ser uma próxima etapa... porque eu acho que ainda não tem sigilo, eles não divulgaram essa política. (E44)

Ressaltamos por fim o papel dos gestores e, em especial, dos profissionais de recursos humanos. A partir do relato 13, observamos que, para E6, além da construção de uma nova cultura pautada no respeito à diversidade, como mencionado, os profissionais da gestão de pessoas, representados pela personagem discursiva "psicólogos", devem ter um papel ativo na supressão do preconceito, não só esperando as demandas dos membros organizacionais, mas também indo em busca dos envolvidos caso haja alguma situação de homofobia.

(13) Existem muitas empresas que fazem eventos, palestras da diversidade. Eles vão deixando claro o companheirismo dentro do trabalho, independente da sua sexualidade, da sua religião, de sua cor. [...] Eu já passei por empresas que têm psicólogos, que fazem esse trabalho, que quando, de repente, surge alguma situação, eles vão em busca e conversam com os funcionários. (E6)

Diante das análises desenvolvidas, notamos percepções e vivências sobre as políticas de diversidade claramente marcadas pelo descompasso entre o discurso e a prática, bem como causas para esse descompasso e propostas para a otimização/ incremento da efetividade de tais políticas, sob a ótica de homossexuais masculinos a quem essas políticas se destinam. Cabe-nos, agora, refletir as repercussões desses indícios para a administração organizacional e, em especial, para o trabalho da diversidade nas organizações. 


\section{Reflexões finais}

O presente artigo teve por objetivo analisar a experiência profissional de homossexuais masculinos, a partir das vivências e percepções dos mesmos a respeito das políticas de diversidade sexual implementadas nas organizações. Por meio das ponderações do empírico, foi possível perceber que o percurso semântico das políticas de diversidade é notadamente marcado pela temática do descompasso entre o discurso e a prática. Dentre as fundamentações apontadas para esse descompasso, ressaltamos, primeiramente, a perpetuação de violências e barreiras operadas contra os homossexuais nas organizações. $\mathrm{Na}$ análise realizada, observamos que, mesmo com a adoção das políticas de diversidade, piadas, sanções arbitrárias, concessões de direitos e oportunidades distintas das oferecidas aos heterossexuais, entre outras violências já denunciadas por autores como Siqueira e Zauli-Fellows (2006), Croteau e Hedstrom (1993), Elliott (1993) e Sanches (2006), perduram no contexto organizacional, minando a eficácia de tais políticas. Destacamos ainda que para os entrevistados tais agressões têm se tornado cada vez mais sutis e escamoteadas.

Outra violência a ser ressaltada é a pressão simbólica exercida sobre os trabalhadores homossexuais para que não revelem sua identidade sexual. Conforme elucidado, os sujeitos dessa pesquisa sentem-se impelidos a ocultarem sua identidade homossexual, ou seja, a permanecerem "no armário". Tal fato, retomando a literatura explorada, pode ser relacionado à representação hegemônica da masculinidade em nossa sociedade (KIMMEL, 1998). Como discutido na seção anterior, é possível observarmos que, no âmbito das organizações, a homossexualidade é aceita desde que os sujeitos se aproximem, ou ao menos aparentem se aproximar, dos atributos hegemônicos social e historicamente valorizados. Assim como proposto por Eccel e Flores-Pereira (2008), percebemos que nas organizações reproduz-se e reforça-se a hierarquia social presente dentre as masculinidades, construindo uma palavra de ordem que determina o enquadramento dos sujeitos ao padrão heteronormativo para que tenham acesso a determinadas oportunidades ou, caso contrário, sua marginalização.

Essa consideração se mostra ainda mais evidente nas passagens em que os enunciadores relatam serem excluídos de cargos de alto nível hierárquico e/ou daqueles que possuem maior contato com o público externo; ou identificam os negros, deficientes e travestis como objeto certo de discriminação por não poderem ocultar as características que os tornam minoria. Salientamos ainda, em consonância com Ferreira (2007), os malefícios dessa violência, na medida em que se exige que uma dimensão tamanhamente importante para a construção das subjetividades, a sexualidade, seja continuamente oprimida no contexto do trabalho.

Associado ao acometimento das violências, observamos a má atuação dos gestores como um dos fundamentos para o descompasso existente entre o discurso e a prática das políticas de diversidade. Os problemas no nível gerencial relacionam-se, como já apontado por Irigaray (2007), a certa permissividade, bem como aos preconceitos arraigados por parte dos gerentes, os quais adotam posturas, muitas vezes, assediadoras. Soma-se a isso, o despreparo dos mesmos para lidar com as situações de homofobia e para o trabalho da diversidade nas organizações.

E, por fim, os enunciadores elucidaram a descrença de que o preconceito possa ser, por meio das políticas de diversidade, erradicado no espaço organizacional. Bourdieu (2007) nos mostra que a marginalização dos homossexuais, entre outras minorias, está centrada em questões culturais, baseada em valores e crenças compartilhados que, ao mesmo tempo em que determinam comportamentos pautados na dominação masculina, impõem a exclusão dos que se distanciam do ideal construído. Nesse contexto, enfatizamos que a supressão dos preconceitos operados em face dos não-heterossexuais não poderá se concretizar apenas por 
ações executadas no âmbito das organizações, exigindo-se a ação conjunta de outras instituições e da sociedade. Argumentamos, entretanto, que as organizações de trabalho devem adotar uma postura ativa nesse processo e, neste esteio, apontaremos algumas reflexões para a gestão da diversidade e para as relações de trabalho.

Uma primeira reflexão importante se mostrou nesses primeiros trechos em que as percepções sobre as políticas e as fundamentações dessas concepções foram abordadas. Observamos que nos relatos destacados, a problemática da ineficiência da gestão da diversidade foi tratada não só considerando o grupo minoritário ao qual os sujeitos dessa pesquisa pertencem, o de homossexuais, mas também outras minorias. Como se percebeu, ao discutirem os motivos que os fazem descrer nas políticas de diversidade, os entrevistados indicaram o problema da ascensão da mulher, a violência ao negro, a exclusão dos deficientes. Tal fato, para nós, pode ser considerado um indicativo de um senso coletivo de minoria, ancorado possivelmente na percepção de que a marginalização que todos eles sofrem é de natureza semelhante. Diante dessa constatação, ousaremos a estender a discussão que se segue às minorias de forma geral, buscando, com isso, refletir sobre o trabalho da diversidade de maneira mais ampla.

Entre as sugestões dos enunciadores bem como as experiências das quais emergiram possíveis caminhos para o incremento/ otimização da efetividade das políticas de diversidade, inicialmente, destacamos a relevância do papel do gestor. No que se refere a esse aspecto, ressaltamos que é indispensável o comprometimento da alta administração e das gerências com as políticas de diversidade. Enfatizamos, primeiramente, que não é necessário que haja situações de homofobia para que exista a mobilização da cúpula estratégica, da ouvidoria e da área de gestão de pessoas. Como apontado na apreciação do empírico, um valor tão destacado nas organizações, a proatividade, pode e deve ser da mesma forma empregado nessas questões, buscando se antecipar à ocorrência das violências e atuar efetivamente para que essas não aconteçam. Outra possibilidade é adotar programas de recompensa para os gestores, de modo a gratificar e reforçar comportamentos inclusivos das minorias por parte dos mesmos.

Conjuntamente, julgamos imprescindível trazer para a formação gerencial o debate sobre tal tema, nos diversos treinamentos e outras atividades pedagógicas executadas no cenário organizacional, assim como o desenvolvimento de competências gerenciais para a supressão das violências e o trabalho da diversidade nas organizações. A qualquer gerente de gestão de pessoas cumpre se empenhar, assim como os demais gerentes, em reproduzir a mensagem de apoio a não discriminação na empresa. Essa, inclusive, é uma das formas de se conseguir que as políticas antidiscriminatórias alcancem a relação interpessoal. Ressaltamos também nesse processo a importância das instituições de ensino e o papel do professor nas escolas de Administração. Consideramos necessário que o processo educacional não se limite à formação de pessoas tecnicamente capacitadas, mas vise a educá-las criticamente, ultrapassando a formalidade e incluindo a discussão de questões políticas, como a diversidade cultural e a sexualidade.

É determinante também que as políticas adotadas e as expectativas sobre as mesmas não sejam impostas, mas sim, sejam fruto de um processo dialogado, tanto para que os membros organizacionais, de modo geral, se conscientizem sobre a sua relevância, quanto para que as minorias, a quem se destinam essas políticas, tenham clareza sobre todo o processo. Nessa pesquisa pudemos perceber que um dos motivos para a não adesão às políticas até então formuladas é a desconfiança pela falta de informação. Salientamos que uma possível estratégia para elucidar essas questões é a definição de um código de ética por meio da gestão participativa, também uma pauta da responsabilidade social.

O emprego da autoridade e a punição das ações discriminatórias configuram outra 
linha de ação fundamental na supressão das violências. Conforme propõem Lucas e Kaplan (1994, p. 36), "as empresas não podem ditar as crenças de seus empregados, mas elas podem ditar um comportamento adequado no ambiente de trabalho", um comportamento que esteja distante de toda e qualquer manifestação discriminatória. Neste esteio, podem-se implementar canais de comunicação que possibilitem informar as situações de assédio e agressão vivenciadas no contexto do trabalho e, consequentemente, favoreçam a identificação dos agressores e a tomada de ações referentes.

Afirmamos, entretanto, que a limitação das ações gerenciais a um esquema de punições, pode desencadear impactos negativos, na medida em que propicia que as violências tomem formas cada vez mais veladas. Como argúem Galeão-Silva e Alves (2002) e Irigaray (2007), a ineficiência das políticas de diversidade se dá por processos de preconceito arraigados por parte dos membros organizacionais, culminando na perpetuidade das agressões. Nesse sentido, faz-se indispensável que, concomitantemente, se promova a conscientização no processo de erradicação do preconceito, o que remete às questões culturais abordadas pelos sujeitos de pesquisa. Reafirmamos, assim, a relevância de se fomentar discussões e palestras que lancem luz sobre o tema da diversidade e possibilitem, com isso, a reflexão.

Finalizando nossas reflexões, apontamos para a necessidade de uma revisão no posicionamento ético da gestão no que se refere à implementação das políticas de diversidade. Conforme já denunciado por Irigaray (2007) e corroborado pelos sujeitos dessa pesquisa, as políticas de diversidade muitas vezes acabam por se desviar do interesse em mitigar as violências e atingir as desigualdades sociais, focando, sobretudo, no alcance dos objetivos organizacionais e em interesses de ordem econômica e mercadológica. É preciso, assim, que se retome o foco em práticas realmente comprometidas com a proteção dos alvos de discriminação das possíveis violências, barreiras, exclusões e preconceitos que eles possam sofrer no ambiente de trabalho. Ademais, salientamos a necessidade do desenvolvimento de novos estudos na área. Esclarecemos que tal demanda não se relaciona apenas a termos protocolares de um artigo científico, mas a um debate a ser fomentado no respectivo campo de estudo, visando a gerar conhecimento e esperança de melhoria nas relações de trabalho e nas relações sociais. 


\section{Referências}

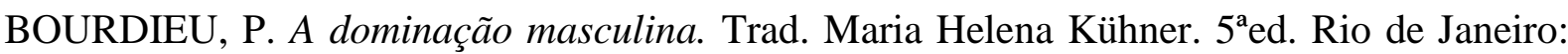
Bertrand Brasil, 2007.

CARRIERI, A. de P. Formas de assédio moral na trajetória profissional de trabalhadores homossexuais masculinos: um estudo em capitais do Brasil. Belo Horizonte: Universidade Federal de Minas Gerais, 2008. (Relatório de projeto de pesquisa financiado pelo CNPq, Edital MCT-CNPq/MS-SCTIE-DECIT - nº 26/2006).

CARRIERI, A. de P. O Fim do "Mundo Telemig": a transformação das significações culturais em uma empresa de telecomunicações. 326f. Tese (Doutorado em Administração) Universidade Federal de Minas Gerais, Belo Horizonte, 2001.

CHUNG, Y. B. Career decision making of lesbian, gay and bisexual individuals. The Career Development Quarterly, v. 44, n. 2, p. 178-186, dez. 1995.

CONNELL, R. W. Masculinities and Globalization In: Men and Masculinities, Sage Publications, v.1, n.1, Jul., 1998.

CROTEAU, J. M.; HEDSTROM, S. M. Integrating commonality and difference: the key to career counseling with lesbian women and gay man. The Career Development Quarterly, v. 41, p. 201-209, 1993.

ECCEL, C. S.; FLORES-PEREIRA, M. T. A inserção da "diversidade" homossexual em uma livraria de shopping Center: um estudo crítico. In.: XXXII ENCONTRO ANUAL DA ANPAD. Anais... Rio de Janeiro, 2008.

ELLIOT, J. E. Career development with lesbian and gay clients. The Career Development Quarterly, v. 41, n. 3, p. 210-226, mar. 1993.

FARIA, A. A. M. de; LINHARES, P. de T. F. S. O preço da passagem no discurso de uma empresa de ônibus. Cadernos de Pesquisa, Belo Horizonte, v. 10, p. 32- 38, 1993.

FERNANDES, C. A. Análise do discurso: reflexões introdutórias. Goiânia: Trilhas Urbanas 2005.

FERREIRA, R. C. O gay no ambiente de trabalho: análise dos efeitos de ser gay nas organizações contemporâneas. Brasília: Dissertação de Mestrado, FACE, 2007.

FLEURY, M. T. M. Gerenciando a diversidade cultural: experiências de empresas brasileiras. Revista de Administração de Empresas. São Paulo, v. 40, n.3, p. 18-25, jul./set. 2000.

FLORES-PEREIRA, M. T.; ECCEL, C. S. Diversidade nas organizações: uma introdução ao tema. In.: BITENCOURT, C. (org) Gestão contemporânea de pessoas: novas práticas, conceitos tradicionais. 2 ed. Porto Alegre: Bookman, 2010.

GAlEÃO-SILVA, L. G.; ALVES, M. A. A Crítica do Conceito de Diversidade nas 
Organizações. In: II ENCONTRO DE ESTUDOS ORGANIZACIONAIS. Anais... Recife, 2002.

GUEDES, M. N. Terror psicológico no trabalho. São Paulo: LTr, 2003.

GODELIER, M. La production des Grands Hommes. Paris: Fayard, 1996.

GÓIS, J. B. H. Desencontros: as relações entre os estudos sobre a sexualidade e os estudos de gênero no Brasil. In: LOPES, Denílson; BENTO, Berenice; ABOUD, Sérgio; GARCIA, Wilton. Imagem \& Diversidade Sexual. Estudos da Homocultura. São Paulo: Nojosa Edições, p. 42-48, 2004.

HEBL, M. R.; GRIFFITH, K. H. The disclosure dilemma for gay men and lesbians: "coming out" at work. Journal of Applied Psychology, 87(6), 1191-1199, 2002.

INSTITUTO ETHOS. Indicadores Ethos de Responsabilidade social. Disponível em: < http://www.ethos.org.br/docs/conceitos_praticas/indicadores/default.asp>. Acesso em: Abril de 2008.

IRIGARAY, H. A. R. Políticas de Diversidade nas Organizações: Uma Questão de Discurso? In.: XXXI ENCONTRO ANUAL DA ANPAD. Anais... Rio de Janeiro, 2007.

KIMMEL, M. S. A produção simultânea de masculinidades hegemônicas e subalternas. Horizontes Antropológicos, Porto Alegre, ano 4, n. 9, Outubro, 1998.

LUCAS, J.; KAPLAN, M. Unlocking the corporate closet. Training e Development, January 1994.

MAINGUENEAU, D. Termos-chave da análise do discurso. Belo Horizonte: Editora UFMG, 1998.

MARRE, J. L. História de vida e método biográfico. Cadernos de Sociologia, Porto Alegre, v. 3, n. 3, p. 89-141, jan./jul. 1991.

NKOMO, S. M.; COX Jr, T. Diversidade e Identidade nas Organizações. In.: CLEGG, S. R.; HARDY, C.; NORD, W. R. Handbook de Estudos Organizacionais, v. 1. Ed. Atlas: São Paulo, 1999.

PRADO, M. A. M ; MACHADO, F. V. Preconceito contra homossexualidades: a hierarquia da invisibilidade. São Paulo: Cortez, 2008.

RODRIGUES, R. L. de F. A temática ambiental no discurso da Companhia Vale do Rio Doce: Jornal Vale Notícias - Minas. 2004. 144 f. Dissertação (Mestrado em Linguiística) Universidade Federal de Minas Gerais, Belo Horizonte, 2004.

SANCHES, V. K. C. A discriminação por orientação sexual no contrato de trabalho. Dissertação de Mestrado do Centro de Ciências Jurídicas e Sociais - Programa de pósgraduação, Pesquisa e Extensão em Direito da PUC-Paraná. Curitiba: 2006 
SIQUEIRA, M.; ZAULI-FELLOWS, A. Diversidade e Identidade Gay nas Organizações. In: IV ENCONTRO NACIONAL DE ESTUDOS ORGANIZACIONAIS. Anais... Porto Alegre, 2006.

UMBELINO, C. A orientação sexual no mercado de trabalho: uma abordagem psicossocial e legal. Disponível em<http://www.artciencia.com/Admin/Ficheiros/CRISTIAN124.pdf>. Acessado em: 15 de abril de 2008.

VERGARA, S. C. Métodos de Pesquisa em Administração. São Paulo: Editora Atlas S.A., 2005.

WARD, J.; WINSTANLEY, D. Coming out at work: performativity and the recognition and renegotiation of identity. The Sociological Review, p.447-475. 2005. 